\title{
WIENER AND DETOUR INDICES OF A NEW TYPE OF NANOSTAR DENDRIMERS
}

\author{
A. Karbasioun, Ali Reza Ashrafi \\ Institute of Nanoscience and Nanotechnology, University of Kashan, \\ Kashan 87317-51167, Iran \\ ashrafi@kashanu.ac.ir
}

\begin{abstract}
The Wiener and detour indices of a molecular graph $\mathrm{G}$ are defined as the sum of the lengths of all shortest and longest paths between the vertices of G. In this paper the exact formulae for the Wiener and detour indices of a new type of nanostar dendrimers are given.
\end{abstract}

Key words: nanostar dendrimer; molecular graph; Wiener index, detour index

\section{ВИНЕРОВИ И ПОВРАТНИ ИНДЕКСИ ЗА НОВ ТИП ДЕНДРИМЕРИ ВО ФОРМА НА НАНОЛВЕЗДА}

\begin{abstract}
За молекуларните графови се дефинирани Винерови (Wiener) и повратни индекси кои се дефинирани како сума од должините на сите најкуси и најдолги патишта помеѓу пресеците во графот G. Во овој труд се изведени формули за Винеровите и повратните индекси за нов тип дендримери во форма на наноsвезда.
\end{abstract}

Клучни зборови: дендример во форма на наноSвезда; молекуларен граф; Винерови индекси, повратен индекс

\section{INTRODUCTION}

Nanostar dendrimers are part of a new group of macromolecules that appear to be photon funnels just like artificial antennas. The topological study of these macromolecules is the subject of this article.

Throughout this paper a graph means finite simple graph without multiple edges and loops. The set of vertices and edges of a graph $G$ are denoted by $V(G)$ and $E(G)$, respectively. The distance $d_{G}(u, v)(d(u, v)$ for short) between two vertices $u, v \in V(G)$ of a connected graph $G$ is the length of a shortest path connecting them. Suppose $\mathfrak{I}$ denotes the set of all finite graphs and $\mathfrak{R}$ is the set of real numbers. A map Top from $\mathfrak{I}$ into $\mathfrak{R}$ is called a topological index, if $\operatorname{Top}(H)=\operatorname{Top}(G)$, for all pairs $(H, G)$ of isomorphic graphs.

The concept of "topological index" was first proposed by Hosoya [1] for characterizing the topological nature of a graph. Such graph invariants are usually related to the distance function

$$
d(-,-): V(G) \times V(G) \longrightarrow R .
$$

Recently, this part of Mathematical Chemistry was named "Metric Graph Theory". The first topological index of this type was proposed in 1947 by the chemist Harold Wiener, [2]. It is defined as the sum of all distances between vertices of the graph under consideration. In the last meeting of International Academy of Mathematical Chemistry, professor Roberto Todeschini announced that he and his team improved MOLE $\mathrm{db}-$ Molecular Descriptors Data Base [3, 4] for working with more than thousand molecular descriptors. The MOLE $\mathrm{db}$ is a free on-line database constituted of 1124 molecular descriptors calculated on 234773 molecules that allows the user to search for a specific group of molecules and analyze the corresponding values of molecular descriptors and to save an output file with the values of a block of 
molecular descriptors calculated on a group of molecules.

Suppose $G$ is a graph with the vertex set $V(G)$ $=\left\{v_{1}, v_{2}, \ldots, v_{n}\right\}$. In Metric Graph Theory, the distance matrix of $G$ is defined as $D(G)=\left[d_{i j}\right]$, where $d_{i j}=d\left(v_{i}, v_{j}\right)$. The detour matrix $D D=\left[d d_{i j}\right]$ can be defined for $\mathrm{G}$ with entries $d d_{i i}=0$ and $d d_{i j}, i \neq j$, as the maximum distance between vertices $v_{i}$ and $v_{j}$. The detour matrix was introduced in graph theory some time ago by F. Harary [5] for describing the connectivity in directed graphs. The detour matrix, in contrast to the distance matrix that records the length of the shortest path between vertices, records the length of the longest distance between each pair of vertices. This matrix remained unknown to chemists until the publication by Amić and Trinajstić [6]. The detour index was introduced a year later by late Istvan Lukovits [7]. Amić and Trinajstić discussed the detour index in their paper, and gave it the name of Wiener-like index. The computation of the detour matrix was presented in a paper by Trinajstić, Nikolić and Mihalić [8] and the whole story about the detour matrix, detour index, and its uses in chemistry are summarized in [9]. We encourage the readers to consult the book of Janežič, Miličević, Nikolić and Trinajstić [10] and a paper by John [11] and the references therein for more information about this topic.

The problem of computing the topological indices of nanostructures was raised by Diudea and his co-authors. In some research papers [12-18] they computed the Wiener index of nanotubes and tori. In $[19,20]$, the authors presented some methods for calculation of the Wiener index and resonance energy of benzenoid systems which are extendable to nanomaterials. In recent years, some authors worked on computing the Wiener, PI, Schultz and Szeged indices of the chemical graphs of some nanomaterials, [21-30].

This paper addresses the problem of computing the Wiener and detour indices of an infinite class of nanostar dendrimers. We choose these two topological indices because of their correlations with some physico-chemical properties of molecules. Our notation is standard and taken mainly from the standard books of graph theory.

\section{RESULT AND DISCUSSION}

Throughout this paper $\mathrm{G}[\mathrm{n}]$ denotes the molecular graph of a nanostar dendrimer with exactly n generation (Figs 1-2). We first calculate the Wiener and detour matrices of the graph $G[n]$ and then compute the Wiener and detour indices of these nanostars. At first, we introduce two concepts which are important in our calculations. Suppose $G$ and $H$ are graphs such that $V(H) \subseteq$ $V(G)$ and $E(H) \subseteq E(G)$. Then we call $H$ to be a subgraph of $G$. $H$ is called isometric, if for each $x$, $y \in V(H), d_{H}(x, y)=d_{G}(x, y)$.

In Figure 3, four isometric subgraphs of $G[n]$ are depicted. From this figure, it is clear that $G[n]$ is constructed from the subgraphs isomorphic to $B$ and the core (Fig. 2). To compute the Wiener and detour indices of $\mathrm{G}[\mathrm{n}]$, we calculate matrices $W A_{1}$, $W A_{2}, W A_{3}$ and $W B$ which are the Wiener matrices of the subgraphs $A_{1}, A_{2}, A_{3}$ and $B$, respectively. Suppose $D_{i}$ and $D_{i}^{\prime}$ are $8 \times 8$ and $8 \times 60$ matrices in which each entry is equal to $i$ and $M$ is the Wiener matrix of the core.

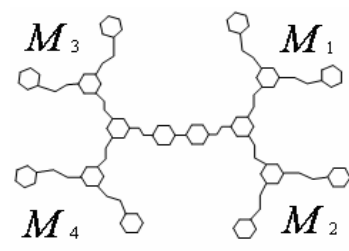

Fig. 1. The molecular graph of $\mathrm{G}[1]$

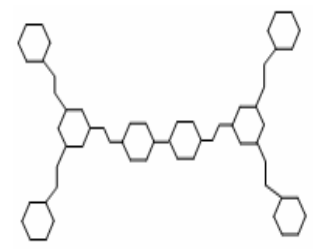

Fig. 2. The core of $\mathrm{G}[\mathrm{n}]$
To construct the Wiener matrix of $G[n]$, it is enough to calculate the distance matrix between a subgraph isomorphic to $B$ and core, distance matrix between two subgraphs isomorphic to $B$ (see $A_{2}$ and $A_{3}$ in Fig. 3) and the Wiener matrix of the core. The distance matrix between a subgraph isomorphic to $B$ and core is equal to the sum of the Wiener matrix of the subgraph $A_{1}, W A_{1}$, and the matrix $D_{i}^{\prime}$, where $i=1(P)-1$ such that $P$ is a minimum path connecting a vertex of core to a vertex of $B$ and $1(P)$ denotes the length of $P$. We now calculate the distance matrix between two subgraphs isomorphic to $B$. To do this, we assume that $B_{1}$ and $B_{2}$ are two subgraphs isomorphic to $B$ and $P$ is a minimum path connecting a vertex of $B_{1}$ to a vertex of $B_{2}$. Obviously, there are two separate cases that one of the end vertices of $P$ is a vertex of a hexagon of $G[n]$ or two end vertices of $P$ are not belong to a hexagon. In the first case, the distance matrix $D\left(B_{1}, B_{2}\right)$ between $B_{1}$ and $B_{2}$ is equal to $W A_{3}+D_{i}$ and for the second $D\left(B_{1}, B_{2}\right)=W A_{2}+$ $D_{i}$. From Fig. 1, one can see that to partition the 
molecular graph of $G[n]$ into a core together with four isomorphic subgraphs $M_{1}[n], \ldots, M_{4}[n]$. We name each of $M_{1}[n], \ldots, M_{4}[n]$, to be a branch of $G$ and $M[n]=M_{1}[n] \cup \ldots \cup M_{4}[n] .$. Obviously, each of branches $M_{i}[n], 1 \leq i \leq 4$, has exactly two isomorphic components $M_{i}^{1}[n]$ and $M_{i}^{2}[n]$. Moreover, the core and branches constitute a partition for $G[n]$. Every subgraph $M_{i}[n], 1 \leq i \leq 4$, has exactly $2^{n+1}-2$ subgraphs isomorphic to $B$ such that degree of vertices of their hexagons are 2 in $G$, say $Y_{1 k}^{i}, 1 \leq i \leq 2^{n-1}, 1=1,2$ and $k=1,2,3,4$. We now define $s_{1}, \ldots, s_{8}$ as follows:

- $s_{1}$ is the summation of distances between vertices of $Y_{11}^{i} \quad Y_{21}^{j}$ and $Y_{12}^{i}$ as well as $Y_{13}^{i}$, $Y_{23}^{j}$ and $Y_{14}^{i}, Y_{24}^{j}$, for each of $i$ and $j, 1 \leq i$ $\neq j \leq 2^{n-1}$,

- $s_{2}$ is the summation of distances between vertices of $Y_{23}^{j}, Y_{13}^{i}$, and $Y_{11}^{i}, Y_{21}^{j} ; Y_{23}^{j}$, $Y_{13}^{i}$ and $Y_{12}^{i}, Y_{22}^{j} ; Y_{14}^{i}, Y_{24}^{j}$, and $Y_{11}^{i}, Y_{21}^{j}$; $Y_{14}^{i}, Y_{24}^{j}$, and $Y_{12}^{i}, Y_{22}^{j}$ for each of $i$ and $j$, $1 \leq i \neq j \leq 2^{n-1}$,

- $s_{3}$ is the summation of distances between vertices of $Y_{1 k}^{i}$ and $Y_{2 k}^{j}$, for each of $i, j$ and $k, 1 \leq i \neq j \leq 2^{n-1}$ and $k=1,2,3,4$,

- $s_{4}$ is the summation of distances between the vertices of $M_{i}^{1}[n]$ and $M_{i}^{2}[n-1]$,

- $S_{5}$ is the summation of distances between vertices of $Y_{1 k}^{i}$ and $Y_{2 k}^{j}$ in $M_{k}[n-1]$,
- $S_{6}$ is the summation of distances between vertices of $Y_{13}^{i}, Y_{23}^{j}$, from $M_{1}[n-1]$ and $Y_{14}^{i}, Y_{24}^{j}$, from $M_{2}[n-1]$,

- $s_{7}$ is the summation of distances between vertices of $M_{2}[n]$ and $M_{1}[1]$, as well as $M_{3}[n]$ and $M_{4}[1]$,

- $s_{8}$ is the summation of distances between other vertices of $M_{i}^{1}[n]$ and $M_{i}^{2}[1]$.
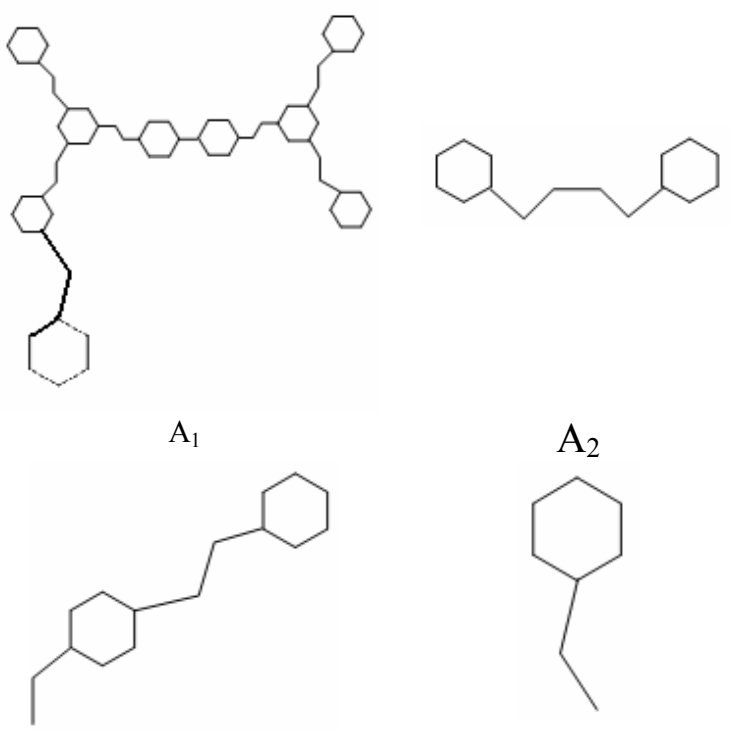

$\mathrm{A}_{2}$

$\mathrm{A}_{3}$

B

Fig. 3. Some subgraphs of $G[n]$

In Table 1 , the Wiener matrix of $G[1]$ is computed. By definition of $s_{1}, \ldots, s_{8}$, one can prove the following equalities:

Table 1

The Wiener Matrix of G[1].

\begin{tabular}{cccccccccc}
\hline \hline & $\mathrm{C}$ & $\mathrm{B}_{1}$ & $\mathrm{~B}_{2}$ & $\mathrm{~B}_{3}$ & $\mathrm{~B}_{4}$ & $\mathrm{~B}_{5}$ & $\mathrm{~B}_{6}$ & $\mathrm{~B}_{7}$ & $\mathrm{~B}_{8}$ \\
\hline $\mathrm{C}$ & $\mathrm{M}$ & $\mathrm{A}_{1}$ & $\mathrm{~A}_{1}$ & $\mathrm{~A}_{1}$ & $\mathrm{~A}_{1}$ & $\mathrm{~A}_{1}$ & $\mathrm{~A}_{1}$ & $\mathrm{~A}_{1}$ & $\mathrm{~A}_{1}$ \\
$\mathrm{~B}_{1}$ & $\mathrm{~A}_{1}$ & $\mathrm{~B}$ & $\mathrm{~A}_{2}+\mathrm{D}_{13}$ & $\mathrm{~A}_{2}+\mathrm{D}_{13}$ & $\mathrm{~A}_{2}+\mathrm{D}_{28}$ & $\mathrm{~A}_{2}+\mathrm{D}_{28}$ & $\mathrm{~A}_{2}+\mathrm{D}_{28}$ & $\mathrm{~A}_{2}+\mathrm{D}_{28}$ & $\mathrm{~A}_{2}+\mathrm{D}_{3}$ \\
$\mathrm{~B}_{2}$ & $\mathrm{~A}_{1}$ & $\mathrm{~A}_{2}+\mathrm{D}_{3}$ & $\mathrm{~B}$ & $\mathrm{~A}_{2}+\mathrm{D}_{13}$ & $\mathrm{~A}_{2}+\mathrm{D}_{13}$ & $\mathrm{~A}_{2}+\mathrm{D}_{28}$ & $\mathrm{~A}_{2}+\mathrm{D}_{28}$ & $\mathrm{~A}_{2}+\mathrm{D}_{28}$ & $\mathrm{~A}_{2}+\mathrm{D}_{28}$ \\
$\mathrm{~B}_{3}$ & $\mathrm{~A}_{1}$ & $\mathrm{~A}_{2}+\mathrm{D}_{28}$ & $\mathrm{~A}_{2}+\mathrm{D}_{28}$ & $\mathrm{~B}$ & $\mathrm{~A}_{2}+\mathrm{D}_{28}$ & $\mathrm{~A}_{2}+\mathrm{D}_{28}$ & $\mathrm{~A}_{2}+\mathrm{D}_{13}$ & $\mathrm{~A}_{2}+\mathrm{D}_{13}$ & $\mathrm{~A}_{2}+\mathrm{D}_{3}$ \\
$\mathrm{~B}_{4}$ & $\mathrm{~A}_{1}$ & $\mathrm{~A}_{2}+\mathrm{D}_{28}$ & $\mathrm{~A}_{2}+\mathrm{D}_{28}$ & $\mathrm{~A}_{2}+\mathrm{D}_{3}$ & $\mathrm{~B}$ & $\mathrm{~A}_{2}+\mathrm{D}_{28}$ & $\mathrm{~A}_{2}+\mathrm{D}_{28}$ & $\mathrm{~A}_{2}+\mathrm{D}_{13}$ & $\mathrm{~A}_{2}+\mathrm{D}_{13}$ \\
$\mathrm{~B}_{5}$ & $\mathrm{~A}_{1}$ & $\mathrm{~A}_{2}+\mathrm{D}_{28}$ & $\mathrm{~A}_{2}+\mathrm{D}_{28}$ & $\mathrm{~A}_{2}+\mathrm{D}_{13}$ & $\mathrm{~A}_{2}+\mathrm{D}_{13}$ & $\mathrm{~B}$ & $\mathrm{~A}_{2}+\mathrm{D}_{3}$ & $\mathrm{~A}_{2}+\mathrm{D}_{28}$ & $\mathrm{~A}_{2}+\mathrm{D}_{28}$ \\
$\mathrm{~B}_{6}$ & $\mathrm{~A}_{1}$ & $\mathrm{~A}_{2}+\mathrm{D}_{28}$ & $\mathrm{~A}_{2}+\mathrm{D}_{28}$ & $\mathrm{~A}_{2}+\mathrm{D}_{13}$ & $\mathrm{~A}_{2}+\mathrm{D}_{3}$ & $\mathrm{~A}_{2}+\mathrm{D}_{13}$ & $\mathrm{~B}$ & $\mathrm{~A}_{2}+\mathrm{D}_{28}$ & $\mathrm{~A}_{2}+\mathrm{D}_{28}$ \\
$\mathrm{~B}_{7}$ & $\mathrm{~A}_{1}$ & $\mathrm{~A}_{2}+\mathrm{D}_{13}$ & $\mathrm{~A}_{2}+\mathrm{D}_{13}$ & $\mathrm{~A}_{2}+\mathrm{D}_{28}$ & $\mathrm{~A}_{2}+\mathrm{D}_{28}$ & $\mathrm{~A}_{2}+\mathrm{D}_{28}$ & $\mathrm{~A}_{2}+\mathrm{D}_{28}$ & $\mathrm{~B}$ & $\mathrm{~A}_{2}+\mathrm{D}_{3}$ \\
$\mathrm{~B}_{8}$ & $\mathrm{~A}_{1}$ & $\mathrm{~A}_{2}+\mathrm{D}_{13}$ & $\mathrm{~A}_{2}+\mathrm{D}_{3}$ & $\mathrm{~A}_{2}+\mathrm{D}_{28}$ & $\mathrm{~A}_{2}+\mathrm{D}_{28}$ & $\mathrm{~A}_{2}+\mathrm{D}_{28}$ & $\mathrm{~A}_{2}+\mathrm{D}_{28}$ & $\mathrm{~A}_{2}+\mathrm{D}_{13}$ & $\mathrm{~B}$ \\
\hline \hline
\end{tabular}




$$
\begin{aligned}
& \mathrm{s}_{1}=\sum_{\mathrm{i}=1}^{\mathrm{n}} 2^{2 \mathrm{i}+1} \cdot(10 \mathrm{i}+3)=-\frac{8}{9} \cdot 4^{\mathrm{n}}+\frac{80}{3} \cdot 4^{\mathrm{n}} \cdot \mathrm{n}+\frac{8}{9} \\
& \mathrm{~s}_{2}=\sum_{\mathrm{i}=1}^{\mathrm{n}} 2^{2 \mathrm{i}+2} \cdot(10 \mathrm{i}+18)=\frac{704}{9} \cdot 4^{\mathrm{n}}+\frac{160}{3} \cdot 4^{\mathrm{n}} \cdot \mathrm{n}-\frac{704}{9} \\
& \mathrm{~s}_{3}=\sum_{\mathrm{j}=1}^{\mathrm{n}} \sum_{\mathrm{i}=1}^{\mathrm{j}} 4 \cdot 2^{\mathrm{j}-2+\mathrm{i}} \cdot(10 \mathrm{i}-7)=\frac{80}{3} \cdot 4^{\mathrm{n}}+68 \cdot 2^{\mathrm{n}}-\frac{124}{9}-\frac{488}{9} \cdot 4^{\mathrm{n}} \\
& \mathrm{S}_{4}=\sum_{\mathrm{l}=3}^{\mathrm{n}} \sum_{\mathrm{k}=2}^{1-1} \sum_{\mathrm{i}=1}^{1-k} 2^{1+\mathrm{i}+1} \cdot(5(1+\mathrm{i})-(5 \mathrm{k}+2))=-\frac{968}{9} \cdot 4^{\mathrm{n}}+\frac{80}{3} \cdot 4^{\mathrm{n}} \cdot \mathrm{n}-56 \cdot 2^{\mathrm{n}}+156 \cdot 2^{\mathrm{n}} \cdot \mathrm{n}-20 \cdot 2^{\mathrm{n}} \cdot \mathrm{n}^{2}+\frac{1472}{9} \\
& \mathrm{~S}_{5}=\sum_{\mathrm{j}=2}^{\mathrm{n}} \sum_{\mathrm{i}=1}^{\mathrm{j}-1} 2^{\mathrm{i}+\mathrm{j}+1} \cdot(5(\mathrm{i}+\mathrm{j})-7)=136 \cdot 2^{\mathrm{n}}-40 \cdot 2^{\mathrm{n}} \cdot \mathrm{n}-\frac{488}{9} \cdot 4^{\mathrm{n}}+\frac{80}{3} \cdot 4^{\mathrm{n}} \cdot \mathrm{n}-\frac{736}{9} \\
& \mathrm{~S}_{6}=\sum_{\mathrm{j}=2}^{\mathrm{n}} \sum_{\mathrm{i}=1}^{\mathrm{j}-1} 2^{\mathrm{i}^{i+j+3}} \cdot(5 \cdot(\mathrm{i}+\mathrm{j})+18)=\frac{448}{9} \cdot 4^{\mathrm{n}}+\frac{320}{3} \cdot 4^{\mathrm{n}} \cdot \mathrm{n}-256 \cdot 2^{\mathrm{n}}-160 \cdot 2^{\mathrm{n}} \cdot \mathrm{n}+\frac{1856}{9} \\
& \mathrm{~S}_{7}=\sum_{\mathrm{j}=3}^{\mathrm{n}} \sum_{\mathrm{i}=1}^{\mathrm{j}-2} 3 \cdot 2^{\mathrm{j}+1} \cdot(5 \mathrm{i})=\sum_{\mathrm{j}=2}^{\mathrm{n}} \sum_{\mathrm{i}=1}^{\mathrm{j}-1} 2^{\mathrm{i}+\mathrm{j}+2} \cdot(5(\mathrm{i}+\mathrm{j})+3)=-\frac{496}{9} \cdot 4^{\mathrm{n}}+\frac{160}{3} \cdot 4^{\mathrm{n}} \cdot \mathrm{n}+112 \cdot 2^{\mathrm{n}}-80 \cdot 2^{\mathrm{n}} \cdot \mathrm{n}-\frac{512}{9} \\
& \mathrm{~S}_{8}=\sum_{\mathrm{l}=3}^{\mathrm{n}} \sum_{\mathrm{k}=2}^{1-1} \sum_{\mathrm{i}=1}^{1-k} 3 \cdot 2^{1+\mathrm{i}} \cdot(5(1+\mathrm{i})-(5 \mathrm{k}+2))=\sum_{\mathrm{j}=3}^{\mathrm{n}} \sum_{\mathrm{i}=1}^{\mathrm{j}-2} 2^{\mathrm{j}+2} \cdot(5 \mathrm{i})=160 \cdot 2^{\mathrm{n}}-100 \cdot 2^{\mathrm{n}} \cdot \mathrm{n}+20 \cdot 2^{\mathrm{n}} \cdot \mathrm{n}^{2}-160
\end{aligned}
$$

By a simple calculation with Maple, one can see that

$$
s_{1}+s_{2}+\ldots+s_{8}=320.4^{n} \cdot n+164.2^{n}-144.4^{n}-224.2^{n} \cdot n-20 .
$$

Therefore we prove the following theorem,

Theorem 1: The Wiener index of $G=G[n]$ is computed as follows:

$$
W(G)=-55424.2^{n}+4480.2^{n} \cdot n+4096.4^{n}+20480.4^{n} \cdot n+9048.2^{n+3}+502
$$

Proof. By definition of $A_{1}, A_{2}, A_{3}, B, M, D_{\mathrm{i}}$ and $D_{i}^{\prime}$ and above calculations, we have:

$$
\begin{aligned}
\mathrm{W}(\mathrm{G}) & =64\left(\mathrm{~s}_{1}+\mathrm{s}_{2}+\ldots+\mathrm{s}_{8}\right)+\left(-80 \cdot 2^{\mathrm{n}}+40 \cdot 2^{\mathrm{n}} \cdot \mathrm{n}+80\right) \sum_{\mathrm{i}, \mathrm{j}} \mathrm{d}_{\mathrm{ij}}^{\prime}+\mathrm{W}\left(\mathrm{A}_{1}\right)\left(2^{\mathrm{n}+3}-8\right) \\
& +\mathrm{W}\left(\mathrm{A}_{2}\right)\left(-8 \cdot 2^{\mathrm{n}} \cdot \mathrm{n}+32 \cdot 4^{\mathrm{n}}-52 \cdot 2^{\mathrm{n}}+20\right)+\mathrm{W}\left(\mathrm{A}_{3}\right)\left(-16 \cdot 2^{\mathrm{n}}+8 \cdot 2^{\mathrm{n}} \cdot \mathrm{n}+16\right)+ \\
& +\mathrm{W}(\mathrm{B})\left(2^{\mathrm{n}+3}-8\right)+\mathrm{W}(\mathrm{M}) \\
& =64\left(320 \cdot 4^{\mathrm{n}} \cdot \mathrm{n}+164 \cdot 2^{\mathrm{n}}-144 \cdot 4^{\mathrm{n}}-224 \cdot 2^{\mathrm{n}} \cdot \mathrm{n}-20\right)+480\left(-80 \cdot 2^{\mathrm{n}}+40 \cdot 2^{\mathrm{n}} \cdot \mathrm{n}+80\right) \\
& +64\left(2^{\mathrm{n}+3}-8\right)+416\left(-8 \cdot 2^{\mathrm{n}} \cdot \mathrm{n}+32.4^{\mathrm{n}}-52 \cdot 2^{\mathrm{n}}+20\right)+368\left(-16 \cdot 2^{\mathrm{n}}+8 \cdot 2^{\mathrm{n}} \cdot \mathrm{n}+16\right) \\
& +8984\left(2^{\mathrm{n}+3}-8\right)+21558 \\
& =-55424 \cdot 2^{\mathrm{n}}+502+4480 \cdot 2^{\mathrm{n}} \cdot \mathrm{n}+4096 \cdot 4^{\mathrm{n}}+20480 \cdot 4^{\mathrm{n}} \cdot \mathrm{n}+9048 \cdot 2^{\mathrm{n}+3} \cdot
\end{aligned}
$$

To compute the detour index of $G[n]$, we define the quantities $t_{1}, \ldots, t_{8}$ similar to $s_{1}, \ldots, s_{8}$ by changing distance into longest distance. Define $t_{1}$, $\ldots, t_{8}$ as follows:

- $t_{1}$ is the summation of maximum distances between vertices of $\mathrm{Y}_{11}^{\mathrm{i}}, \mathrm{Y}_{21}^{\mathrm{j}}$ and $\mathrm{Y}_{12}^{\mathrm{i}}$, $\mathrm{Y}_{22}^{\mathrm{j}}$, as well as $\mathrm{Y}_{13}^{\mathrm{i}}, \mathrm{Y}_{23}^{\mathrm{j}}$ and $\mathrm{Y}_{14}^{\mathrm{i}}$, $Y_{24}^{\mathrm{j}}$, for each of $\mathrm{i}$ and $\mathrm{j}, 1 \leq i \neq j \leq 2^{n-1}$,

- $t_{2}$ is the summation of maximum distances between vertices of $\mathrm{Y}_{23}^{\mathrm{j}}, \mathrm{Y}_{13}^{\mathrm{i}}$ and $\mathrm{Y}_{11}^{\mathrm{i}}$, $\mathrm{Y}_{21}^{\mathrm{j}} ; \mathrm{Y}_{23}^{\mathrm{j}}, \mathrm{Y}_{13}^{\mathrm{i}}$ and $\mathrm{Y}_{12}^{\mathrm{i}}, \mathrm{Y}_{22}^{\mathrm{j}} ; \mathrm{Y}_{14}^{\mathrm{i}}, \mathrm{Y}_{24}^{\mathrm{j}}$ and $\mathrm{Y}_{11}^{\mathrm{i}}, \mathrm{Y}_{21}^{\mathrm{j}} ; \mathrm{Y}_{14}^{\mathrm{i}}, \quad \mathrm{Y}_{24}^{\mathrm{j}}$ and $\mathrm{Y}_{12}^{\mathrm{i}}$, $\mathrm{Y}_{22}^{\mathrm{j}}$, for each of $\mathrm{i}$ and $\mathrm{j}, 1 \leq i \neq j \leq 2^{n-1}$,

- $t_{3}$ is the summation of maximum distances between vertices of $Y_{1 k}^{i}$ and $Y_{2 k}^{j}$, for each of $i, j$ and $k, 1 \leq i \neq j \leq 2^{n-1}$ and $k=1,2,3,4$,

- $t_{4}$ is the summation of maximum distances between the vertices of $\mathrm{M}_{\mathrm{i}}^{1}[\mathrm{n}]$ and $\mathrm{M}_{\mathrm{i}}^{2}[\mathrm{n}-1]$,

- $t_{5}$ is the summation of maximum distances between vertices of $\mathrm{Y}_{1 \mathrm{k}}^{\mathrm{i}}$ and $\mathrm{Y}_{2 \mathrm{k}}^{\mathrm{j}}$ in $M_{k}[n-1]$, 
- $t_{6}$ is the summation of maximum distances between vertices of $\mathrm{Y}_{13}^{\mathrm{i}}, \mathrm{Y}_{23}^{\mathrm{j}}$ from $M_{1}[n-$ 1] and $Y_{14}^{\mathrm{i}}, Y_{24}^{\mathrm{j}}$ from $M_{2}[n-1]$,

- $\quad t_{7}$ is the summation of maximum distances between vertices of $M_{2}[n]$ and $M_{1}[1]$, as well as $\mathrm{M}_{3}[\mathrm{n}]$ and $M_{4}[1]$,

$\mathrm{B}=2^{\mathrm{n}+3}-8$

$\mathrm{A}_{1}=2^{\mathrm{n}+3}-8$

$\mathrm{A}_{2}=-8 \cdot 2^{\mathrm{n}} \cdot \mathrm{n}+20+32 \cdot 4^{\mathrm{n}}-52 \cdot 2^{\mathrm{n}}$

$\mathrm{A}_{3}=-16.2^{\mathrm{n}}+8 \cdot 2^{\mathrm{n}} \cdot \mathrm{n}+16$

$\mathrm{D}_{\mathrm{i}}^{\prime}=-112 \cdot 2^{\mathrm{n}}+56 \cdot 2^{\mathrm{n}} \cdot \mathrm{n}+112$

$\mathrm{t}_{1}=\sum_{\mathrm{i}=1}^{\mathrm{n}} 2^{2 \mathrm{i}+1} \cdot(14 \mathrm{i}+5)=\frac{8}{9} \cdot 4^{\mathrm{n}}+\frac{112}{3} \cdot 4^{\mathrm{n}} \cdot \mathrm{n}-\frac{8}{9}$

$\mathrm{t}_{2}=\sum_{\mathrm{i}=1}^{\mathrm{n}} 2^{2 \mathrm{i}+2} \cdot(14 \mathrm{i}+22)=\frac{832}{9} \cdot 4^{\mathrm{n}}+\frac{224}{3} \cdot 4^{\mathrm{n}} \cdot \mathrm{n}-\frac{832}{9}$

$\mathrm{t}_{3}=\sum_{\mathrm{j}=1}^{\mathrm{n}} \sum_{\mathrm{i}=1}^{\mathrm{j}} 4 \cdot 2^{\mathrm{j}-2+\mathrm{i}} \cdot(14 \mathrm{i}-9)=\frac{112}{3} \cdot 4^{\mathrm{n}} \cdot \mathrm{n}+92 \cdot 2^{\mathrm{n}}-\frac{664}{9} \cdot 4^{\mathrm{n}}-\frac{164}{9}$

$\mathrm{t}_{4}=\sum_{\mathrm{l}=3}^{\mathrm{n}} \sum_{\mathrm{k}=2}^{1-1} \sum_{\mathrm{i}=1}^{1-\mathrm{k}} 2^{1+\mathrm{i}+1} \cdot(7(1+\mathrm{i})-(7 \mathrm{k}+2))=-\frac{1336}{9} \cdot 4^{\mathrm{n}}+\frac{112}{3} \cdot 4^{\mathrm{n}} \cdot \mathrm{n}-72 \cdot 2^{\mathrm{n}}+212 \cdot 2^{\mathrm{n}} \cdot \mathrm{n}-28 \cdot 2^{\mathrm{n}} \cdot \mathrm{n}^{2}+\frac{1984}{9}$

$\mathrm{t}_{5}=\sum_{\mathrm{j}=2}^{\mathrm{n}} \sum_{\mathrm{i}=1}^{\mathrm{j}-1} 2^{\mathrm{i}+\mathrm{j}+1} \cdot(7(\mathrm{i}+\mathrm{j})-9)=184 \cdot 2^{\mathrm{n}}-56 \cdot 2^{\mathrm{n}} \cdot \mathrm{n}-\frac{664}{9} \cdot 4^{\mathrm{n}}+\frac{112}{3} \cdot 4^{\mathrm{n}} \cdot \mathrm{n}-\frac{992}{9}$

$\mathrm{t}_{6}=\sum_{\mathrm{j}=2}^{\mathrm{n}} \sum_{\mathrm{i}=1}^{\mathrm{j}-1} 2^{\mathrm{i}+\mathrm{j}+3} \cdot(7 \cdot(\mathrm{i}+\mathrm{j})+22)=\frac{320}{9} \cdot 4^{\mathrm{n}}+\frac{448}{3} \cdot 4^{\mathrm{n}} \cdot \mathrm{n}-256 \cdot 2^{\mathrm{n}}-224 \cdot 2^{\mathrm{n}} \cdot \mathrm{n}+\frac{1984}{9}$

$\mathrm{t}_{7}=\sum_{\mathrm{j}=2}^{\mathrm{n}} \sum_{\mathrm{i}=1}^{\mathrm{j}-1} 2^{\mathrm{i}+\mathrm{j}+2} \cdot(7(\mathrm{i}+\mathrm{j})+5)=-\frac{656}{9} \cdot 4^{\mathrm{n}}+\frac{224}{3} \cdot 4^{\mathrm{n}} \cdot \mathrm{n}+144 \cdot 2^{\mathrm{n}}-112 \cdot 2^{\mathrm{n}} \cdot \mathrm{n}-\frac{640}{9}$

$\mathrm{t}_{8}=\sum_{\mathrm{j}=3}^{\mathrm{n}} \sum_{\mathrm{i}=1}^{\mathrm{j}-2} 2^{\mathrm{j}+2} \cdot(7 \mathrm{i})=224 \cdot 2^{\mathrm{n}}-140 \cdot 2^{\mathrm{n}} \cdot \mathrm{n}+28 \cdot 2^{\mathrm{n}} \cdot \mathrm{n}^{2}-224$

A simple calculation by Maple shows that

$t_{1}+t_{2}+\ldots+t_{8}=448.4^{n} \cdot n+316.2^{n}-240.4^{n}-320.2^{n} \cdot n-76$.

Therefore we have the following theorem:

Theorem 2: The detour index of $G=G[n]$ is computed as follows:

$d d(G)=-74624.2^{n}+6272.2^{n} \cdot n+4096.4^{n}+28672.4^{n} \cdot n+12452.2^{n+3}+630$.

Proof. By definition of $A_{1}, A_{2}, A_{3}, B, M, D_{i}$ and $D_{i}^{\prime}$ and above calculations, we have:

$$
\begin{aligned}
\operatorname{dd}(G) & =64\left(448 \cdot 4^{n} \cdot n-76+316 \cdot 2^{n}-240 \cdot 4^{n}-320 \cdot 2^{n} \cdot n\right)+480\left(-112 \cdot 2^{n}+56 \cdot 2^{n} \cdot n+112\right) \\
& +124\left(2^{n+3}-8\right)+608\left(-8 \cdot 2^{n} \cdot n+20+32 \cdot 4^{n}-52 \cdot 2^{n}\right)+592\left(-16 \cdot 2^{n}+8 \cdot 2^{n} \cdot n+16\right) \\
& +12328\left(2^{n+3}-8\right)+29718 \\
& =-74624 \cdot 2^{n}+630+6272 \cdot 2^{n} \cdot n+4096 \cdot 4^{n}+28672 \cdot 4^{n} \cdot n+12452 \cdot 2^{n+3}
\end{aligned}
$$




\section{CONCLUSION}

In this paper a novel method for computing the Wiener and detour matrices of chemical graphs are presented. If a molecular graph $\mathrm{G}$ can be decomposed into cycles and paths then a similar method as given in the paper can be applied to compute the Wiener and detour matrices of G. So, the method given in this paper is general for such molecular graphs.

Acknowledgment. The authors are greatly indebted to the referees for their valuable suggestions and giving historical notes given in the introduction of this paper.

\section{REFERENCES}

[1] H. Hosoya, Topological Index. A Newly Proposed Quantity Characterizing the Topological Nature of Structural Isomers of Saturated Hydrocarbons, Bull. Chem. Soc. Japan, 44, 2332-2339 (1971).

[2] H. Wiener, Structural Determination of Paraffin Boiling Points, J. Am. Chem. Soc., 69, 17-20 (1947).

[3] MOLE db - Molecular Descriptors Data Base, Milano Chemometrics and QSAR Research Group, http://michem.disat.unimib.it/mole_db.

[4] R. Todeschini and V. Consonni, Handbook of Molecular Descriptors, WILEY - VCH, Weinheim, 2000.

[5] F. Harary, Graph Theory, Addison-Wesley, Reading, Massachusetts, 1969.

[6] D. Amić, N. Trinajstić, On the Detour Matrix, Croat. Chem. Acta, 68, 53-62 (1995).

[7] I. Lukovits, The Detour Index, Croat. Chem. Acta, 69, 873-882 (1996).

[8] N. Trinajstić, S. Nikolić, Z. Mihalić, On Computing the Molecular Detour Matrix, Int. J. Quantum Chem., 65, 415-419 (1997).

[9] N. Trinajstić, S. Nikolić, B. Lučić, D. Amić and Z. Mihalić, The Detour Matrix in Chemistry, J: Chem. Inf. Comput. Sci., 37, 631-638 (1997).

[10] D. Janežič, A. Miličević, S. Nikolić and N. Trinajstić, Graph-Theoretical Matrices in Chemistry, University of Kragujevac, Kragujevac, 2007.

[11] P. E. John, Ueber die Berechnung des Wiener-Index fuer ausgewaehlte Delta-dimensionale Gitterstrukturen, MATCH Comm. Math. Comp. Chem., 32, 207-219 (1995).

[12] M. V. Diudea, A. Graovac, Generation and graphtheoretical properties of $\mathrm{C}_{4}$-tori, MATCH Commun. Math. Comput. Chem., 44, 93-102 (2001).
[13] M. V. Diudea, I. Silaghi-Dumitrescu, B. Parv, Toranes versus torenes, MATCH Commun. Math. Comput. Chem., 44, 117-133 (2001).

[14] M.V. Diudea, P.E. John, Covering polyhedral tori, MATCH Commun. Math. Comput. Chem., 44, 103-116 (2001).

[15] M. V. Diudea, Toroidal Graphenes from 4-Valent Tori, Bull. Chem. Soc. Jpn., 75, 487-492 (2002).

[16] M. V. Diudea, Hosoya Polynomial in Tori, MATCH Commun. Math. Comput. Chem., 45, 109-122 (2002).

[17] P. E. John, M. V. Diudea, Wiener index of zig-zag polyhex nanotubes, Croat. Chem. Acta, 77, 127-132 (2004).

[18] M.V. Diudea, M. Stefu, B. Parv, P. E. John, Wiener index of armchair polyhex nanotubes, Croat. Chem. Acta, 77, 111-115 (2004).

[19] D. Vukičević, N. Trinajstić, Wiener indices of benzenoid graphs, Bull. Chemist \& Technoligist Macedonia, 23, 113-129 (2004).

[20] Ivan Gutman, Slavko Radenkovic, A simple formula for calculating resonance energy of benzenoid hydrocarbons, Bulletin of the Chemists and Technologists of Macedonia, 25, 17-21 (2006).

[21] S. Yousefi, A. R. Ashrafi, An exact expression for the Wiener index of a polyhex nanotorus, MATCH Commun. Math. Comput. Chem., 56, 169-178 (2006).

[22] S. Yousefi, A. R. Ashrafi, An algorithm for constructing Wiener matrix of $\mathrm{TUC}_{4} \mathrm{C}_{8}(\mathrm{R})$ nanotubes, Current Nanoscience, 4, 161-165 (2008).

[23] A. R. Ashrafi, S. Yousefi, Computing the Wiener Index of a TUC4C8(S) Nanotorus, MATCH Commun Math Comput Chem, 57, 403-410 (2007).

[24] S. Yousefi, A. R. Ashrafi, An Exact Expression for the Wiener Index of a $\mathrm{TUC}_{4} \mathrm{C}_{8}(\mathrm{R})$ Nanotorus, $J$ Math Chem, 42, 1031-1039 (2007).

[25] A. R. Ashrafi, S. Yousefi, A New Algorithm for Computing Distance Matrix and Wiener Index of Zig-zag Polyhex Nanotubes Nanoscale Res Lett, 2, 202-206 (2007).

[26] L. Xu, H. Deng, The Schultz Molecular Topological Index of $\mathrm{C}_{4} \mathrm{C}_{8}$ Nanotubes, MATCH Commun. Math. Comput. Chem., 59, 421-428 (2008).

[27] S. Chen, Q. Jang, Y. Hou, The Wiener and Schultz Index of Nanotubes Covered by $\mathrm{C}_{4}$, MATCH Commun. Math. Comput. Chem., 59, 429-435 (2008).

[28] M. Eliasi, B. Taeri, Szeged Index of Armchair Polyhex Nanotubes, MATCH Commun. Math. Comput. Chem., 59, 437-450 (2008).

[29] H. Yousefi-Azari, A. R. Ashrafi, A. Bahrami, J. Yazdani, Computing Topological Indices of Some Types of Benzenoid Systems and Nanostars, Asian J. Chem., 20, 15-20 (2008).

[30] A. R. Ashrafi, M. Mirzargar, PI, Szeged and edge Szeged indices of an infinite family of nanostar dendrimers, Indian Journal of Chemistry, 47A, 538-541 (2008). 